\title{
Comportamento dos professores da educação básica na busca da informação para formação continuada
}

\author{
Kelley C ristine $\mathbf{G}$ onçalves $\mathbf{D}$ ias $\mathbf{G}$ asque \\ M estre em ciência da informação pela U niversidade de Brasília. \\ Especialista em literatura brasileira e graduada em biblioteconomia e \\ documentação pela U niversidade de Brasília. Assessora Núcleo \\ Tecnologia do Colégio Marista de Brasília \\ E-mail: Kdias@marista.org.br
}

\section{Sely M aria de Souza Costa}

PhD em ciência da informação pela Loughborough U niversity, Inglaterra. Professora adjunta no Departamento de Ciência da Informação da U niversidade de Brasília

E-mail: selmar@unb.br

\section{Resumo}

O estudo objetiva descrever as características dos docentes e identificar os canais e fontes utilizados, assim como os fatores que influenciam o padrão de comportamento na busca da informação para formação continuada. Utilizou-se como referencial teórico o modelo de busca de informação de Wilson, com enfoque nas necessidades cognitivas dos professores, de acordo com o modelo proposto por Imbernón. Os instrumentos de coleta de dados foram o questionário auto-administrado e a entrevista semi-estruturada. Os resultados mostram que as fontes mais usadas são os livros didáticos e paradidáticos, além de jornais. Concluiu-se que as novas tecnologias ainda não são usadas por professores de educação básica como um recurso cotidiano de apoio à formação continuada, e os canais de informação mais utilizados são os arquivos pessoais, arquivos dos colegas e a biblioteca escolar.

\section{Palavras-chave}

Comportamento informacional - professores educação básica; Biblioteca escolar, busca e uso da informação - formação continuada.

The elementary and secondary school teachers' information seeking behavior on behalf of their own continuing education

\footnotetext{
Abstract

The study aimed to describe those teachers' main characteristics and to identify both information channels and sources they use as well as factors that influence their behavior patterns when seeking information to continuing education. The theoretical framework used has been taken from Thomas Wilson's information seeking model. In this sense, the study focused on those teachers' cognitive needs, according to Imbernon's model. Data collection instruments used comprised the self-

administrated questionnaire and semi-structured interview. The results showed that the most used are the didactic book, the para-didactic book and newspapers. The study main conclusions are that new information technologies have not yet been used as a quotidian resource to support continuing education.
}

Keywords

Behavior information - primary and secundary school teachers; School library, information seeking - continuing education.

\section{INTRO D U ÇÃ O}

0 presente artigo* referese a um estudo de caso realizado nos colégios M aristas da então Província M arista de São Paulo sobre o comportamento informacional dos professores da educação básica na busca de informação para a formação continuada. 0 estudo visou à identificação dos canais e fontes de informações mais utilizados e dos fatores que podem influenciar a busca de informação para suprir necessidades relacionadas à atuação profissional do professor. Buscou também averiguar se o comportamento informacional dos professores da educação básica se diferencia de acordo com os níveis de atuação, áreas do conhecimento, funções, formação acadêmica, faixas etárias e sexo.

0 estudo fundamenta-se na suposição de que as transformações técnico-científicas, econômicas, políticas e sociais determinam aos professores a necessidade de capacitação permanente para que assimilem as inovações tecnológicas, as novas formas de organização de trabalho e os novos modos de produção. Desta forma, o ofício do professor tem se modificado para contemplar um mundo em rápidas e constantes mudanças, no qual a formação continuada de professores entendida como um processo constante de busca e renovação do saber-fazer educativo, que abrange as atividades promovidas ou apoiadas pela instituição e os programas de formação pessoal, deve se caracterizar como uma das condições essenciais para a melhoria do ensino e aprendizagem.

Para tanto, buscaram-se subsídios teóricos na ciência da informação e educação para abordar os principais tópicos referentes ao comportamento informacional, à formação dos professores e ao uso das novas tecnologias para a formação continuada, além do papel que a biblioteca escolar deve desempenhar nesse contexto.

\footnotetext{
* Baseia-se na dissertação de mestrado defendida no D epartamento de Ciência da Informação da U niversidade de Brasília.
} 


\section{COMPORTAMENTO INFORMACIONAL}

Várias áreas do conhecimento como a psicologia, administração, ciências da saúde, comunicação e ciência da informação têm contribuído para os estudos do comportamento informacional humano. $\mathrm{Na}$ ciência da informação, W ilson (1999, p. 249) define comportamento informacional como as atividades de busca, uso e transferência de informação, nas quais uma pessoa se engaja quando identifica as próprias necessidades de informação.

0 termo comportamento informacional - information behaviour - é freqüentemente usado na literatura internacional. No Brasil, o conhecimento sobre comportamento informacional geralmente é abordado sob o rótulo de "estudos de usuários". N o entan to, ambas as abordagens incluem os estudos de necessidades e usos da informação, sempre com a preocupação de identificar e discutir padrões de comportamento informacional nos diferentes campos do saber (C osta, 2001).

0 que se pode depreender dos textos estudados é que 0 comportamento informacional e o estudo de usuários envolvem os seguintes conceitos:

- necessidades de informação - um déficit de informação a ser preenchido e que pode estar relacionado com motivos psicológicos, afetivos e cognitivos.

- busca da informação - ativa e/ ou passiva - o modo como as pessoas buscam informações;

- uso da informação - a maneira como as pessoas utilizam a informação;

- fatores que influenciam o comportamento informacional;

- transferência da informação - o fluxo de informações entre as pessoas;

- estudos dos métodos - identificação dos métodos mais adequados a serem aplicados nas pesquisas.

Sob a ótica do comportamento informacional, os professores atuantes na educação básica são entendidos como usuários de informação, na medida em que esse comportamento é condicionado por necessidades de informação para a sua formação continuada. Assim, torna-se imprescindível abordar a questão da formação do professor.

\section{A FORMAÇÃO DO PROFESSOR E INFRA- ESTRUTURA DE INFORMAÇÃO}

Formação pode ser enten dida como 'a ação ou o efeito de formar ou formar-se; maneira pela qual seconstitui um caráter, mental idade; disposição; constituição'. Esta definição sugere duas idéias: uma, a de processo; outra, a de constituição de conhecimento ou de competência. Portanto, formação diz respeito a um processo de desenvolvimento contínuo para a aquisição de conhecimentos, atitudes e competências gerais.

Em se tratando de formação profissional, formação inicial refere-se à aquisição de conhecimentos de base; e formação continuada ou permanente abrange a formação após a aquisição de base, com caráter de aperfeiçoamento ao longo de toda a vida profissional (Imbernón, 1994, p.13).

A formação continuada é importante para que o professor se atualize constantemente e desenvolva as competências necessárias para atuar na profissão. A idéia de competência parece, então, transbordar os limites dos saberes, ou seja, o professor deve possuir tanto conhecimentos quanto competências profissionais que não se reduzem somente ao domínio dos conteúdos ensinados.

0 conceito de competências, às vezes, criticado como uma perspectiva puramente técnica em contraposição à perspectiva acadêmica, tem recheado as discussões dos professores e estudiosos da área educacional. $\mathrm{N}$ a verdade, não é um conceito novo: surgiu do campo empresarial e financeiro com o objetivo de buscar, por meio de programas de 'capacitação dos recursos humanos', 'reengenharia' ou 'qualidade total', al ternativas para melhorar a produtividade e competitividade em decorrência especialmente do processo de substituição tecnológica que inflige novas formas de trabalho.

O documento básico do Exame $\mathrm{N}$ acional do Ensino $M$ édio (Enem), divulgado pelo Instituto $\mathrm{N}$ acional de Estudos e Pesquisas Educacionais (Inep), define competências como "modalidades estruturais da inteligên cia, ou melhor, ações e operações que utilizamos para estabelecer relações com e entre objetos, situações, fenômenos e pessoas que desejamos oferecer", sendo as habilidades decorrências das competências adquiridas, referindo-se "ao plano imediato do 'saber fazer'". Para Perrenoud (2000, p. 15), competência designa a capacidade de mobilizar diversos recursos cognitivos para enfrentar situações. 


\section{Comportamento dos professores da educação básica na busca da informação para formação continuada}

Assim sendo, competência pode ser entendida como o 'saber fazer' derivado das relações entre o conhecimento que 0 sujeito detém, a experiência adquirida pela prática e a ref lexão sobre a ação pedagógica. Para desenvolvêlas, o professor precisa se inserir em um processo de formação permanente que implica também a busca de informação para construção de novos conhecimentos.

$\mathrm{N}$ esse sentido, o professor deve atuar como um pesquisador garantindo o manejo da pesquisa como "princípio científico e educativo" (D emo, 2002, p. 2). $E$, ao se en gajar em alguma atividade de pesquisa, o professor encontra fontes e recursos diversificados de informação. Entre estas, as novas tecnologias parecem ser um meio relevante de se obterem informações atualizadas de forma rápida e com custo relativamente baixo.

0 avanço das telecomunicações, em especial da Internet, tem diminuído fronteiras e aproximado pessoas, tornando o mundo efetivamente uma aldeia global, como preconizou M CLuhan. A Internet tem sido cada vez mais incorporada ao cotidiano das pessoas, representan do um avanço quanto à formação continuada em todas as áreas, uma vez que proporciona e integra várias ferramentas e recursos diversificados, principalmente para a formação docente, dentre os quais se destacam o correio eletrônico (e-mail); as listas de discussão, as publicações científicas de texto integral, sites com informações específicas para professores e os cursos de educação a distância, que podem favorecer os professores que não têm a oportunidade de fazer um curso presencial. Desta maneira, o professor pode ter um desenvolvimento contínuo dos saberes tornando a própria apren dizagem individualizada. Portanto, as novas tecnologias da informação são, ao mesmo tempo, recurso para a formação do professor e para a elaboração de estratégias de ensino e aprendizagem.

O utro fator que se torna importante observar, quando se fala em formação de professores, atualização continuada, necessidades e busca de informação, é a análise de como a biblioteca escolar se insere nesse contexto, na tentativa de estabelecer todas as relações possíveis para entendimento do problema.

A retórica da sociedade 'reconhece' a importância do papel das bibliotecas escolares como elementos fundamentais no processo de ensino-aprendizagem. No entanto, esse reconhecimento não se traduz, no Brasil, em uma política de implantação, desenvolvimento e avaliação de bibliotecas nas escolas públicas e privadas a partir de parâmetros delineados por profissionais da informação e educadores que definam o que seja uma biblioteca escolar eas suas fun ções no ambien te educativo. Por falta de tais parâmetros, bibliotecas escolares têm sido, geralmente, negligenciadas. $M$ ais que isso, quando existentes, parecem ser consideradas como apêndices do sistema educacional. Essa situação é, no mínimo, incoerente com as propostas de inovação da área educacional.

Tais inovações, conseqüências das transformações pelas quais a educação tem passado, têm sido agregadas pela escola gradualmente e compreendem o repensar do processo de ensino e aprendizagem. $\mathrm{H}$ oje, questiona-se a aula tradicional, centrada no professor como 'transmissor' do conhecimento que restringe a participação do aluno à de um mero receptor, e se propõe que 0 ato de ensinar seja centrado na ação ativa e na interação do educando com o objeto de conhecimento, com a intenção de fazer com que alunos e professores sejam capazes de continuar aprendendo por toda a vida.

A ssim, para que a educação consiga atingir os seus objetivos, é necessário dar ênfase ao papel dos professores como agentes de mudança, mediadores entre a informação e o conhecimento e motivadores do processo de aprendizagem, e também a todos os recursos que eles possam utilizar para facilitar a aprendizagem. Deste modo, as bibliotecas atuantes como um centro de recursos de aprendizagem podem ser consideradas como um desses recursos essenciais no processo de construção do conhecimento do professor e do aluno.

\section{METODOLOGIA}

A metodologia usada no presente estudo compreendeu quatro aspectos fundamentais: a fundamentação teórica em que se baseou a pesquisa, o método de investigação adotado, 0 ambiente em que se realizou 0 estudo e os instrumentos de coleta e análise de dados. N este artigo, destaca-se o referencial teórico usado na pesquisa com o objetivo de contribuir para a discussão de questões relacionadas ao comportamento informacional. Dessa forma, o relato sobre os outros três fatores estão sumariados no parágrafo a seguir.

A pesquisa caracterizou-se como de caráter tanto descritivo quanto analítico, na qual, por meio da técnica de levantamento (survey) com a utilização de 453 questionários auto-administrados e 18 entrevistas, seis em cada colégio, procurou-se descrever, anal isar e discutir os fenômenos relacionados à busca da informação pelos professores no processo de formação continuada. Para o tratamento dos dados quantitativos, utilizou-se o SPSS. 


\section{Kelley C ristine Gonçalves Dias G asque / Sely M aria de Souza C osta}

0 ambiente em que se realizou o estudo é constituído pelas dez escolas vinculadas à província M arista de São Paulo. D essas, foram selecionadas três unidades amostrais - Colégio Marista de Brasília, Colégio Marista Arquidiocesano e Colégio M arista Santa M aria, por apresentarem uma infra-estrutura mínima de informações que dão suporte à formação continuada biblioteca, apoio a cursos, congressos e seminários, ampla assessoria pedagógica, entre outras - , podendo assim ser consideradas representativas dos colégios particulares que têm investimentos nesse âmbito.

\section{Referencial teórico da pesquisa}

A fundamentação teórica deste estudo se baseia nos modelos conceituais de T. Wilson de 1981 e de Imbernón de 1994. 0 modelo de W ilson enfatiza a busca ativa da informação a partir da percepção da necessidade de informação, baseada em duas proposições:

1. a informação é uma necessidade secundária que surge dos tipos mais básicos de necessidades, ditas primárias, como a necessidade de procriação, de alimentação e outros;

2. ao buscar informações, as pessoas, normalmente, deparam-se com barreiras que podem impedi-las de encontrar a informação desejada.

$\mathrm{N}$ esse modelo, as necessidades de informação podem ser definidas como psicológicas, afetivas ou cognitivas, as quais se relacionam com três questões básicas. A primeira diz respeito à personalidade do indivíduo. A segunda, com os papéis que ele desempenha na sociedade, e a terceira, com os vários contextos ambientais (econômicos, tecnológicos, políticos...) que influenciam os diferentes papéis sociais que ele exerce. A partir da percepção da necessidade de informação, o indivíduo, provavelmente, engajar-seá em atividades de busca de informação, nas quais poderão surgir barreiras relacionadas com as questões descritas. N essa perspectiva, os mesmos el ementos que estimulam a busca de informação podem dificultar o processo. A maneira como o indivíduo age durante o processo de busca da informação define o seu comportamento informacional.

Partindo do pressuposto de que os professores da educação básica, por motivação própria e/ou imposição institucional, precisam se atualizar para desenvolver as atividades profissionais, acredita-se que em algum momento poderão se envolver em atividades de busca de informação para suprir tal necessidade. Supõe-se que os professores precisam de informações específicas da área educacional que os ajudem a compreender, a transformar e a desenvolver competências específicas para 0 processo de ensino e aprendizagem. A definição de um conjunto de saberes necessários à atuação profissional dos professores não é fortuita e tampouco formalmente sistematizada, mas fundamenta-se em discussões e pesquisas sobre determinadas concepções de ensino que consideram diferentes modos de formação dos professores. Dentre as várias perspectivas de classificação dessas concepções, destaca-se a sugerida por Gimeno \& Perez Gómez (2000, p. 354), por ter sido baseada na análise de diferentes propostas e enfoques, tendo como diretrizes as contribuições de Zeichner \& Feiman-N emser. Os autores distinguem quatro perspectivas básicas:

Perspectiva acadêmica - 0 ensino é concebido com a função de transmitir informações. 0 professor é um especialista, e sua formação se vincula, essencialmente, ao domínio do conteúdo da disciplina que deve transmitir.

Perspectiva técnica - Propõe dar ao ensino as condições e o rigor científico. 0 ensino é considerado como ciência aplicada na qual o professor deve atuar como um técnico que domina as aplicações do conhecimento científico produzido por outros e transformado em regras de atuação.

Perspectiva prática - A formação dos professores se baseia na aprendizagem da prática, para a prática e a partir da prática. A prática reflexiva, entendida como uma evolução da orientação prática tradicional, propõe uma nova epistemologia da prática profissional centrada no professor como um profissional que se confronta com situações complexas, incertas, mutantes e conflitantes, ou seja, um profissional ref lexivo, portanto com um conhecimento tácito que ativa e elabora durante a própria interven ção. Procura superar a relação linear e mecânica entre o conhecimento científico e técnico e a prática na sala de aula a partir da ref lexão sistemática e compartilhada sobre a prática.

\section{Perspectiva de reflexão na prática para a reconstrução social - Essa perspectiva supera a concepção da prática ref lexiva, embora ambas convirjam em muitos aspectos. Segundo essa visão, o professor é um intelectual orgânico*, com conhecimentos profundos da realidade em que vive e com capacidade para transformá-la.}

\footnotetext{
* Intelectual orgânico é um termo cunhado por Gramsci para se referir aos profissionais que têm a função de organizar, sistematizar e mesmo elaborar o pensamento do grupo social ao qual estão organicamente ligados. Trata-se de um grupo que tem em mão o "poder", "privilégio", ou "força" de direção dentro da sociedade, capaz de conduzir a mesma (Gramsci, 1989).
} 
As quatro concepções manifestam-se nas discussões sobre formação do professor, porém a perspectiva da formação do professor como profissional ref lexivo tem sido intensamente discutida na última década. Para formar esse tipo de profissional, a tendência atual (Tardif, Lessard \& Lahaye, 1991; G authier, 1998) parece ser a de conceber a formação docente como um conjunto de vários saberes para responder às exigências específicas de situações concretas de ensino/ apr erıuı বayerrı.

De maneira mais genérica, mas que parece abranger 0 eixo fundamental da formação do professor, Imbernón (1994, p. 53) propõe um modelo de formação constituído por quatro componentes - o científico, 0 psicopedagógico, o da prática docente e o cultural. Em relação ao último conteúdo, mesmo ciente de que 0 ambiente educacional requer uma boa "bagagem cultural", entende-se que o componente cultural é um saber necessário a todas as profissões, não sendo específico da área educacional. A ssim, esse estudo focalizará, particularmente, o comportamento do docente na busca das informações relacionadas aos outros três componentes propostos por Imbernón, quais sejam:

Informação de conteúdo científico - Refere-se aos assuntos específicos da disciplina ministrada, ou seja, aos conhecimentos da área ou áreas que o professor deverá organizar para a reconstrução por parte dos alunos.

Informação psicopedagógica - Refere-se aos conhecimentos teóricos, práticos e tecnológicos das ciências da educação para sua aplicação no exercício docente. Contempla tanto os aspectos socioeducativos relação entre escola e sociedade, estruturas educativas, políticas e sociais etc. - quanto a metodologia de ensino e aprendizagem - planejamento e programação do trabalho escolar, questões disciplinares, de adaptação dos alunos, desenvolvimento psicológico dos mesmos, entre outros.

Informação sobre a prática docente - Refere-se aos conhecimentos que permitem que o professor estude, reflita, discuta e faça experiências a partir da própria prática. V islumbra uma maior profissionalização, possibilitando que o docente analise as estratégias eaucativas, aentro aa realıaade escolar em aıterentes fases, adquira maior experiência didática, possa se colocar criticamente perante as atividades que realiza e valide os objetivos, conteúdos, métodos e propostas curriculares utilizados em aula. De maneira sucinta, pode-se dizer que a prática docente relaciona-se com a transposição dos componentes científico, psicopedagógico e cultural para a sala de aula.

Dessa forma, foi utilizado como referencial teórico o modelo de busca de informação de Thomas W ilson de 1981, com enfoque nas necessidades cognitivas dos professores, definidas em virtude da concepção de formação do professor como um profissional reflexivo que necessita de informações específicas, de acordo com o modelo proposto por Imbernón (1994), como representado na figura 1. Parte-se da premissa de que as atividades profissionais dos professores da educação básica não podem prescindir do uso das informações referentes às disciplinas ministradas, do conhecimento básico de psicopedagogia que possibilita melhorar a dinâmica do ensino e aprendizagem e, por fim, dos conhecimentos que permitem uma reflexão e avaliação da própria prática profissional a partir da identificação dos canais e fontes de informação mais utilizados e também dos fatores que influenciam a busca de informação.

\section{RESU LTADOS}

0 dados coletados revelaram que a conjunção de fatores ligados às características individuais dos professores, como a formação acadêmica alta (especialização), renda pessoal e familiar acima da média de parte dos trabalhadores brasileiros, carga horária de trabalho de 


\section{Kelley C ristine Gonçalves Dias G asque / Sely M aria de Souza C osta}

20 a 31 horas semanais, juntamente com outros fatores, como a exigência e o apoio do colégio, pode contribuir para a intensificação da busca de informação.

Constatou-se que os livros didáticos, de maneira geral, são as fontes mais usadas pelos professores estudados. Considera-se que, dentre os vários fatores que explicam a vinculação entre professor e livro didático, os mais importantes são, em primeiro lugar, a rotina e a forte tradição pedagógica a que os professores parecem estar submetidos, nas quais o livro didático é ainda tido como a espinha dorsal de quase todos os componentes curriculares. N esse aspecto, mesmo que os professores tenham estruturas adequadas para lecionar, como no caso dos colégios pesquisados, ainda continuam usando o livro intensamente. Percebese 0 uso de outras fontes, tais como revistas, jornais e a Internet, mas não com tanta intensidade quanto o livro didático. Em segundo lugar, o livro didático vem com o suplemento do professor que contém orientações para a elaboração das aulas, mediações e avaliação que facilitam o trabalho do professor, pois uma reclamação constante dos professores foi em relação à falta de tempo. Em terceiro, o livro didático é específico para determinada faixa etária, ou seja, o professor não precisa elaborar material adicional para transpor o conhecimento didaticamente para as crianças, como, por exemplo, no caso de se trabalhar com outras fontes como jornais. E, por fim, todo professor tem o próprio acervo de livros didáticos fornecidos pelas editoras, gratuitamente, fator que o deixa acessível quando necessário.

As novas tecnologias (Internet e computadores) ainda não são usadas como um recurso cotidiano de apoio à formação continuada, apesar de a maioria ter acesso a esses recursos em casa e na escola e se mostrar ciente da sua importância. M ais da metade dos professores avaliou 0 próprio desempenho em relação à utilização desses recursos como bom. Entre os recursos da Internet mais utilizados pelos professores, estão o sistema de busca e o correio eletrônico. Fatores como as pressões ambientais e a demanda por aulas menos expositivas, entre outros, aliados à política do colégio e à propensão individual de aprendizagem dos professores, tendem a ampliar o uso das novas tecnologias para a formação continuada.

Para buscar informações, os canais informais (arquivo pessoal e de colegas) foram reportados como os inicialmente usados na busca de informações, para somente em um segundo momento procurar o canal formal (no caso a biblioteca), o que evidencia a importância da comunicação ou redes informais dentro do colégio.
Diferentemente de outros no Brasil, no presente estudo, a biblioteca escolar se insere no contexto da formação continuada como um recurso importante que complementa outros canais, como se observou pela freqüência de uso assinalada pelos professores estudados. Porém, cabe ressaltar que a percepção que os professores parecem possuir das funções da biblioteca é bastante limitada. O u seja, para eles uma boa biblioteca é aquela que disponibiliza com facilidade um acervo atualizado e diversificado. N esse sentido, questiona-se se a biblioteca escolar, apesar de tentativas concretas de disponibilizar novos produtos e serviços, não rompeu com essa imagem perante o professor, porque a questão cultural é muito forte, ou porque real mente a biblioteca tem se preocupado em apenas atualizar e diversificar o acervo.

Foram observados al guns tópicos interessantes em relação ao uso dos canais e fontes de informação pelos professores. 0 primeiro é que os professores parecem relacionar a formação continuada muito estreitamente com os conteúdos que devem ensinar aos alunos, fato esse que ficou evidenciado, especificamente pelas entrevistas e coincidências de fontes de informação assinaladas no questionário tanto para formação continuada quanto em sala de aula - livros didáticos, jornais, paradidáticos e revistas. Outra constatação do estudo é que os professores usam bastante os meios orais para buscar informações sobre questões específicas de sua área. No entanto, quando buscam informação sobre a disciplina lecionada, ainda impera o livro didático. Q uando o professor busca informação sobre as teorias de ensino e aprendizagem em geral, tende a procurar a pessoa que exerce a função de assessoria ou coordenação pedagógica para depois, se possível, fazer a leitura do livro indicado. N esse caso, realmente buscam mais os 'Iivros técnico-científicos'. Por fim, quando o professor é questionado sobre onde busca as informaç̧ões para a sua prática docente, as fontes são a própria experiência acumulada e os colegas de trabalho. Em relação à busca de conhecimento de ensino-aprendizagem e da prática docente, os resultados mostram primeiro que os professores buscam as pessoas e, posteriormente, os livros.

Os resultados evidenciam dois pontos. 0 primeiro revela a importância das redes informais como canais eficientes e rápidos de se buscarem informações e compartilhar experiências. 0 segundo diz respeito à visão utilitarista da informação, isto é, a primazia desta pelos professores às informações que são fundamentadas na prática docente. A esse respeito, $\mathrm{H}$ ounsell, $\mathrm{M}$ artin $\& N$ eedham (1980, p.7), em uma pesquisa sobre as necessidades de informação dos professores da escola primária na Inglaterra, concluíram que a informação tendia a ser 


\section{Comportamento dos professores da educação básica na busca da informação para formação continuada}

mais valorizada pelos professores quando se baseava na experiência de professores ou de escolas. Tal fato é corroborado por Imbernón (1994, p. 43), ao observar que os professores em formação solicitam basicamente receitas didáticas.

0 que se pode concluir sobre essa questão é que os professores buscam, primeiramente, as fontes ou canais de informações que Ihes estão mais próximos, em detrimento, às vezes, da qualidade dos mesmos, fato este corroborado pela literatura na ciência da informação, como, por exemplo, em Figueiredo (1994), Giacometti (1990) \& Kremer (1981).

N o processo de busca da informação para informação continuada, os fatores que mais dificultam a busca da informação em relação aos contextos pessoal, profissional e ambiental são dificuldade dos professores em gerenciar o tempo, dificuldades em verificar a credibilidade das fontes de informação, falta de conhecimentos técnicos para usar as fontes e canais de informação, falta de clareza quanto ao que é necessário buscar para a formação continuada, falta de plano de carreira para os professores, excesso de atividades propostas pela escola e não-acessibilidade imediata às fontes de informação.

0 modelo teórico no qual essa pesquisa se fundamenta apresenta a proposição de que as pessoas, ao buscarem informações para as suas necessidades, deparam-se com fatores que dificultam ou mesmo inibem a busca da informação. Os fatores que dificultam nesse processo são os mesmos que podem favorecer a busca da informação - características pessoais, papel desempenhado e fatores ambientais (contextos político, social, econômico etc.).

A hipótese levantada nessa pesquisa que estabelecia que o comportamento dos professores da educação básica varia em relação ao nível em que atuam, áreas de conhecimento, função exercida, escolaridade, idade e sexo não foi confirmada. A explicação mais provável pode ser a de que a escola se organiza para atingir sua finalidade. Essa finalidade, por sua vez, parece transcender qualquer outro tipo de influência sobre 0 comportamento dos professores na busca de informação para formação continuada. N esse caso, os professores, como atores dessas organizações, orientam-se também para esse propósito. Portanto, o fato de os professores usarem fontes e canais de informação voltados basicamen te para a sua prática em sala de aula demonstra a dimensão desse fato.
Sobre essa questão, T escarolo (2003), ao estudar a escola como um sistema complexo, considera fundamental entendêla dentro da perspectiva da sua finalidade:

A teleologia, doutrina oposta ao mecanicismo, identifica a presença de metas ou fins orientadores da realidade e considera a finalidade como o princípio explicativo fundamental na organização e nas transformações do universo. É, portanto, a explicação das realidades baseadas nas causas finais, e não na causalidade eficiente.

A constatação de que os padrões de comportamento dos professores na busca da informação para formação continuada não apresentam grandes variações não significa que esse padrão seja exatamente igual. No que concerne à variável sexo, por exemplo, observou-se que as mulheres participam mais dos eventos que acontecem no colégio do que os homens, enquanto, no caso da participação em eventos fora do colégio, a participação masculina é maior. As mulheres também usam mais freqüentemente que os homens fontes de informação diversificadas (paradidáticos, almanaques, enciclopédias e dicionários, mapas e atlas, fitas de vídeo, CD s DVDs), a biblioteca escolar, e usam menos a Internet no local de trabalho.

As prováveis explicações para esses fatos podem estar relacionadas primeiramente com a situação da mulher no mercado de trabalho. Segundo dados do Dieese, existem diferen ças significativas entre homens e mulheres no mercado de trabalho. As mulheres são minoria no mercado de trabal ho e ganham menos do que os homens. A taxa de desemprego é superior à dos homens. Portanto, a dificuldade de inserção no mercado de trabalho tem levado as mulheres a obter maior nível de escolaridade para assegurar a conquista de novas ocupações.

Outro fator é que as mulheres possuem carga horária menor do que os homens. M esmo que, de uma maneira geral, os professores tenham relatado o problema da falta de tempo, ainda assim as professoras que possuem carga horária menor, provavelmente, têm mais tempo para buscar informação para a formação continuada.

\section{ONCLUSÕES}

0 foco de estudo deste trabalho foi a identificação dos padrões de comportamento dos professores da educação básica no que concerne à busca de informações específicas, tais como informações sobre a disciplina ministrada, en sino e aprendizagem e prática docente para a formação continuada por meio de um estudo de caso. 


\section{Kelley C ristine G onçalves Dias G asque / Sely M aria de Souza C osta}

A partir da pesquisa, reconhecese que, embora os estudos de caso apresentem limitações quanto a possíveis generalizações, estudos dessa natureza podem revelar tendências e agregar valor ao corpo de conhecimento da ciência da informação e educação, especificamente porque a quantidade de pesquisas orientadas para os professores da educação básica na busca de informação ainda é ínfima.

Pelos resultados apresentados, observou-se que os professores dos colégios estudados estão preocupados com a formação continuada, o que se traduz pela freqüência com que utilizam os canais e fontes de informação. Contudo, a formação continuada dos professores vincula-se muito estreitamente ao que se deve ensinar aos alunos. Este fato pode ser explicado, em parte, pela teleologia que considera a finalidade como 0 princípio explicativo fundamental nas organizações, visto que não houve sustentação para afirmar que 0 comportamento dos professores da educação básica varia 'significativamente' na busca de informações para formação continuada.

\section{REFERÊN C I AS}

BRASIL. M inistério da Educação. Instituto $\mathrm{N}$ acional de Estudos e Pesquisas Educacionais. Exame $\mathrm{N}$ acional do Ensino Médio. Documento básico. Disponível em: < http//www.inep.gov.br/ >. Acesso em: 21 set. 2001.

COSTA, Sely M. S. M udanças no processo de comunicação científica: o impacto do uso de novas tecnologias. In: COMUNICAÇÃO CIENTÍfICA. Brasília : U niversidade de Brasília, 2000. $144 \mathrm{p}$. (Estudos avançados em Ciência da Informação, v. 1)

DEM O, Pedro. Conhecer e aprender: sabedoria dos limites e desafios. Porto Alegre: Artmed, 2000.

GIMEN O, J.; PÉREZ, A. I. Compreender e transformar o ensino. Trad. Ernani F. da R. Rosa. Porto Alegre : Artmed, 1998.

GRAM SCI, Antônio. Os intelectuais e a organização da cultura. Rio de Janeiro : Civilização Brasileira, 1989.

HADJI, Charles. A formação permanente dos professores: uma necessidade da era da profissionalização. Pátio - revista pedagógica, Porto A legre, n. 17, p. 13-16, maio/ jul. 2001.

IM BERN ÓN, Francisco. La formación del professorado. Buenos Aires : Paidós, 1994.

PERREN OU D, Philippe. Dez novas competências para ensinar: convite à viagem. Porto Alegre : Artmed, 2000.

WILSON, T. D. Models in information behaviour research. Journal of Documentation, v. 55, n. 3, June 1999, p. 249-270. 